\title{
1986 Election Results: Taylor for First VP; Baglin for Second VP
}

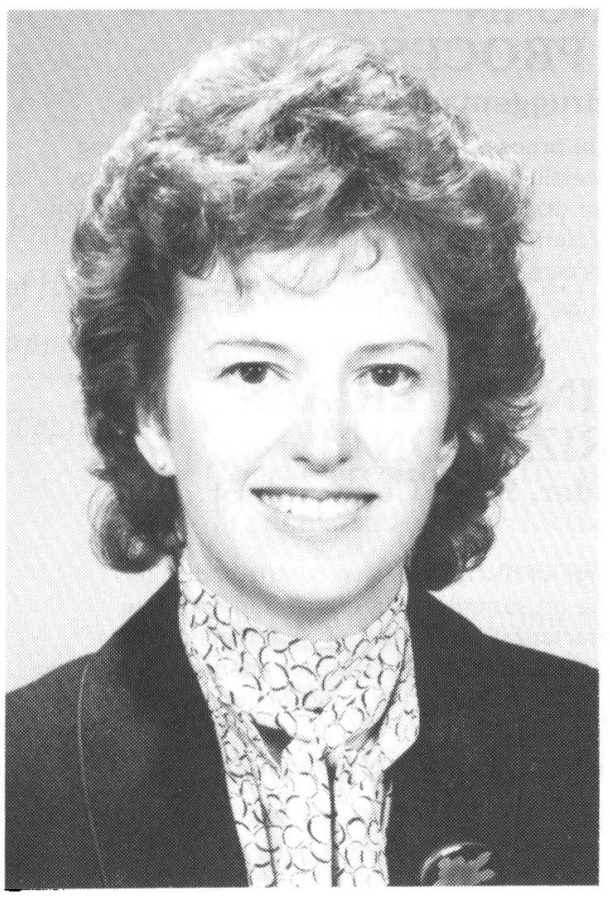

Kathleen C. Taylor, First Vice President

Kathy Taylor, First Vice President, is head, Physical Chemistry Department at GM Research Laboratories. She has served a four-year term as MRS Treasurer, as 1985 Second Vice President, and has served on both the Council and Finance Committee. She conceived and implemented the Graduate Student Award Program in 1980 and played a major role in establishing MRS Headquarters in Pittsburgh.

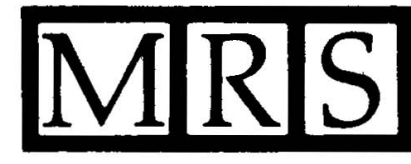

\begin{tabular}{c} 
MATERIALS \\
RESEARCH \\
SOCIETY \\
\hline
\end{tabular}

Kathy Taylor and John Baglin have been selected by the membership of MRS to fill two of the top offices of the Society in 1986, announced MRS President Elton Kaufmann. Kathy Taylor will serve as First Vice President and President-Elect and John Baglin will serve as Second Vice President. They will begin their terms of office Ja nuary 1, 1986

The five winners of the Councillor slots were Robert W. Balluffi, R. P. H. Chang, Noble M. Johnson, Frans Spaepen, and Rustum Roy. These five new Councillors will also begin their three-year terms in January.

The newly elected Officers and Councillors represent a wide range of scientific interests in industry and education and have voiced a number of important goals for the Society. Their past support of the Society and understanding of its purpose will benefit the MRS immensely. With Gordon Pike at the helm as President and Rod Ewing and Clif Draper continuing as Secretary and Treasurer, respectively, our newly elected team can look forward to a year of continued productivity and growth," Kaufmann said.

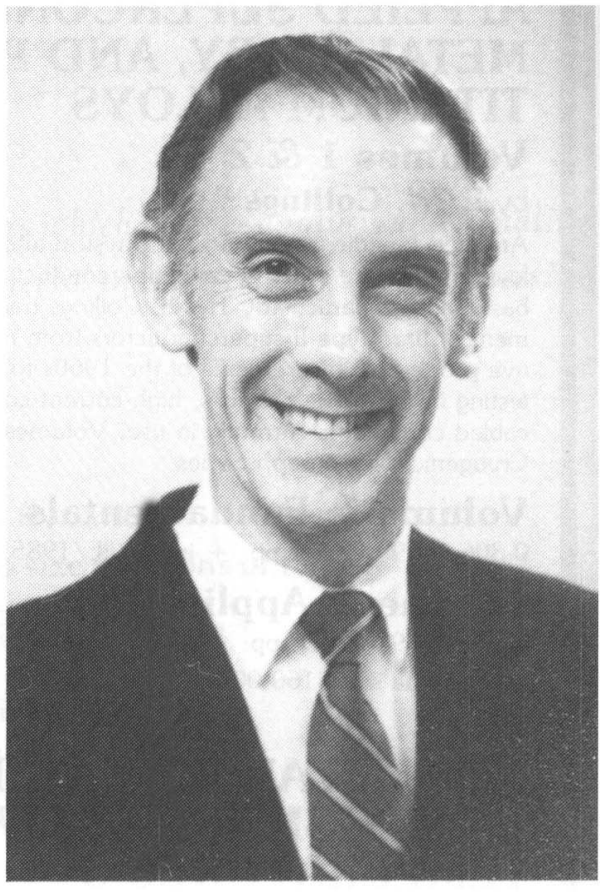

John E. E. Baglin, Second Vice President

John Baglin, Second Vice President, has been with IBM T. J. Watson Research Center since 1972, and was previously assistant professor of Physics at Iowa State University. As chairperson of the 1984 Publications Committee, he established the in-house proceedings publishing operation at the new MRS Headquarters and was also involved in establishing the Journal of Materials Research, which will appear in early 1986. He is a Program Chair of the 1985 MRS Fall Meeting.

\section{Councillors}



Robert W. Balluffi

Robert Balluffi is professor of physical metallurgy at MIT. He has over 20 years of teaching experience and is the author of over 170 papers in the areas of crystal defects, diffusion, and radiation damage. $\mathrm{He}$ is a member of the National Academy of Sciences, and Fellow of the American
Academy of Arts and Sciences, The Metallurgical Society of AIME, and the American Physical Society.



R. P. H. Chang

Bob Chang has been with AT\&T Bell Laboratories since 1971. In 1984, he organized the Society's first symposium on Plasma Synthesis and Etching of Electronic
Materials. This year he was appointed to the newly established position of Chairman, International Relations to promote MRSstyle activities worldwide. He is a Program Chair of the 1986 MRS Fall Meeting.

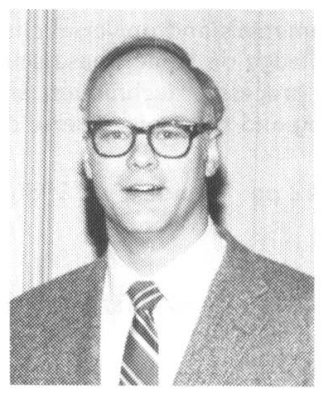

Noble M. Johnson

Noble Johnson is a senior member of the research staff of Xerox Palo Alto Research 
Center. He has chaired two popular MRS symposia, Energy Beam-Solid Interactions and Transient Thermal Processing (1983) and Microscopic Indentification of Electronic Defects in Semiconductors (1985). He has been active in the Society since 1978. He was a Program Chair of the first MRS Spring Meeting, held in Albuquerque in 1984.

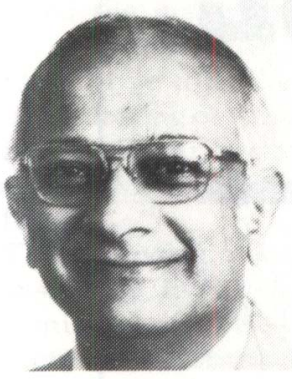

Rustum Roy

Rustum Roy is professor of the Solid State at Pennsylvania State University where he has also been director of the Materials Research Laboratory. He served as the Society's first Secretary and its second President, and annually organizes and runs the cross-disciplinary Symposium $X$ at the Spring and Fall Meetings.



Frans Spaepen

Frans Spaepen, Gordon McKay Professor of Applied Physics at Harvard University, has been an invited speaker at several MRS symposia and is currently chairing the symposium on Phase Transformations in Condensed Systems at the 1985 Fall Meeting. His research interests span phase transformation, formation of new materials with pulsed laser quenching, and interdiffusion and stability in amorphous multilayered films.

"The slate of candidates was top notch this year, and the large return of ballots demonstates a strong interest on the part of the membership in ensuring strong and dynamic leadership for the MRS." Kaufmann remarked. "The new Officers and Councillors are clearly representative of the membership and its interest in the future growth of the Society."

"We wish the new Officers and Councillors great success during the coming year as they tackle many difficult issues, and I encourage all members of the Society to offer advice and support to help them with the job ahead,"Kaufmann said.
Now Available. .

\section{MRS EXTENDED ABSTRACTS}

\author{
MRS Members $\$ 5 \quad$ Nonmembers $\$ 7$
}

New

Beam Induced Chemical Processes

Code EA-5

Edited by R. J. von Gutfeld, J. E. Greene, H. Schlossherg

Fractal Aspects of Materials

Code EA-6

Edited by R. B. Laibowitz, B. Mandelbrot, D. E. Passoja

Nonlinear Optical Materials

Code EA-7

Edited by D. A. B. Miller

\section{Also Available}

Laser Chemical Processing of Semiconductor Devices

Code EA-1

\section{Graphite Intercalation Compounds}

Code EA-2

Alloy Phase Diagrams

Code EA-3

Fractal Aspects of Materials: Metal and Catalyst Surfaces,

Powders and Aggregates

Code EA-4

Send prepayment to Materials Research Society, Publications Department, 9800 McKnight Road, Suite 327, Pittsburgh, PA I 5237; (4 I 2) 367-30 I 2.

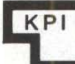

\section{ELECTRON AND ION OPTICS GUNS / SOURCES}

$5 \mathrm{eV}$ to $100 \mathrm{keV}$

High Brightness Electron Sources

High Brightness Ion Sources

UHV Electrostatic Optics, Power Supplies

Charge Neutralization Systems

Accessories for SEM, MBE, ESD, SIMS, AUGER, e- Lithography

Custom UHV Apparatus



UP TO $20 \mathrm{keV}$ AVAILABLE ON $70 \mathrm{~mm}\left(2 \frac{3}{4} \mathrm{in}.\right)$ CONFLAT

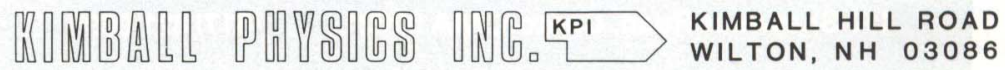

(603) $878-1616$

UHV ELECTRON \& ION SOURCES/OPTICS/SYSTEMS 


\section{for \\ GAS and VACUUM ANALYSIS and CONTROL}

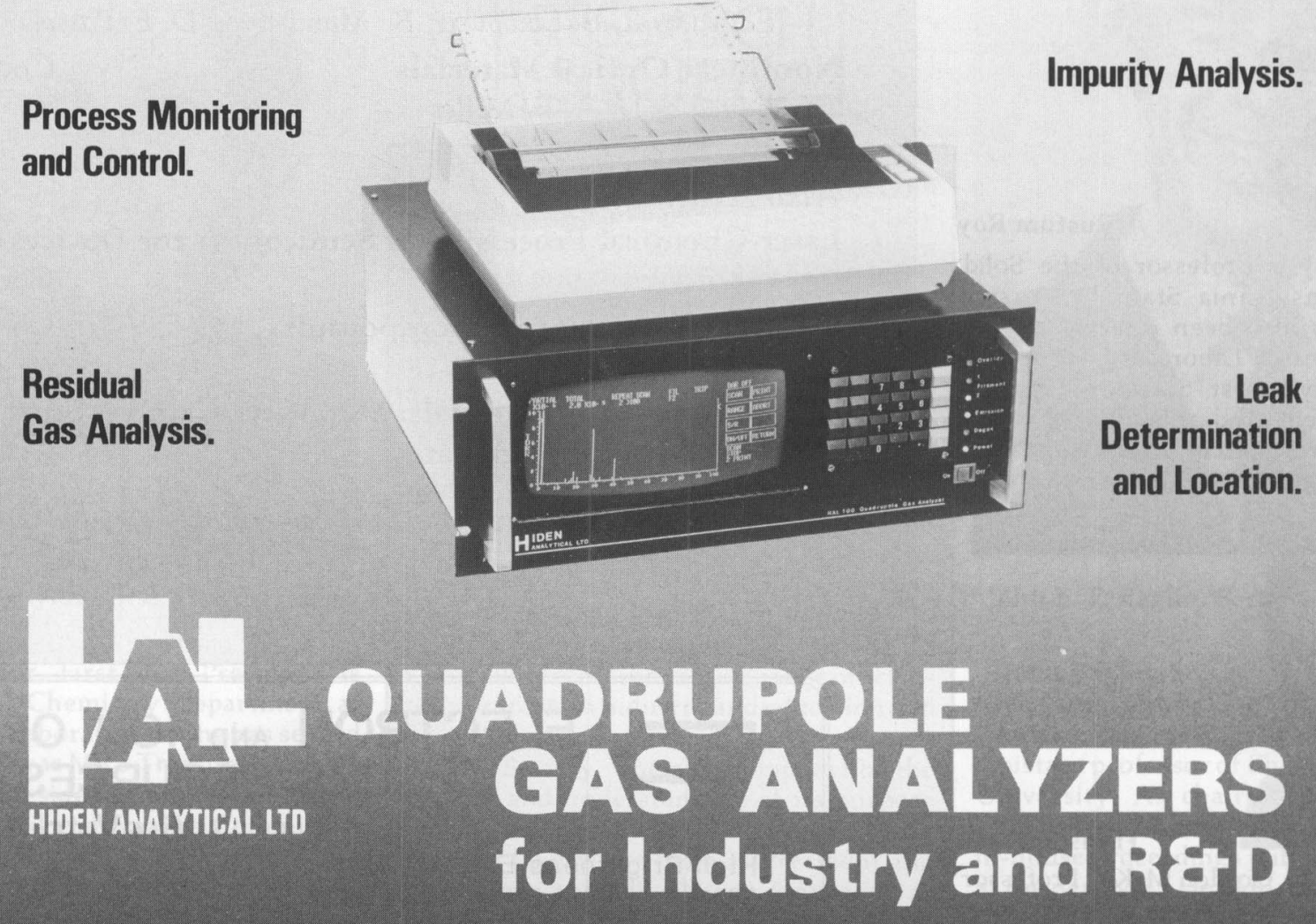

Mass range options to 300 amu

- $R$ and D versions with software control of resolution.

- SIMS probes for high pressure and UHV applications.

- Pressure reduction modules for process monitoring and control. Manual and automatic valve operation.

Distributed in the USA by:

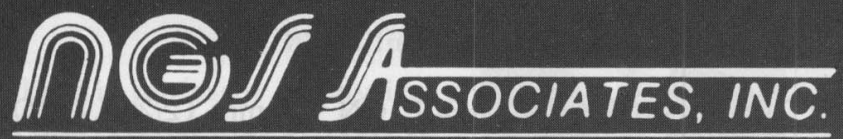

110 Shawmut Road, Canton, MA 02021
Software Labelled Control Keys

System control is both very fast and very easy

Dual Mass/Pressure Display

Alternate scanning of two independent mass ranges with independent pressure selection. Simultaneous display and printout.

Trend Analysis Mode

Continuous output from 16 mass channels with individual autorange on each channel over six decades of pressure.

\section{Cracking Pattern Library}

Integral mass search eliminates all but bestfit compounds. Library capacity exceeds 100 species.

Faraday and Electron Multiplier Detection

For routine vacuum and UHV to $5 \times 10^{-14}$ torr.

\section{Manufactured by:}

HIDEN ANALYTICAL LTD

WARRINGTON, ENGLAND WA1 4RW 